\title{
Resistin Is Closely Related to Systemic Inflammation in Obstructive Sleep Apnea
}

\author{
Yasushi Yamamoto ${ }^{a}$ Satoru Fujiuchi ${ }^{b}$ Mie Hiramatsu ${ }^{a}$ Yutaka Nishigaki ${ }^{b}$ \\ Akinori Takeda $^{a}$ Yuka Fujita ${ }^{a}$ Yasuhiro Yamazaki ${ }^{a}$ \\ Departments of a Respiratory Medicine and ${ }^{b}$ Clinical Research, National Hospital Organization, Dohoku Hospital, \\ Asahikawa, Japan
}

For editorial comment see p. 375

\section{Key Words}

Adipose tissue $\cdot$ Cytokines $\cdot$ Inflammation $\cdot$ Obstructive sleep apnea $\cdot$ Resistin

\begin{abstract}
Background: Obstructive sleep apnea (OSA) is closely related to systemic inflammation. Resistin is an adipocytederived cytokine (adipokine) that may link obesity with inflammation. Objective: We aimed to investigate whether incremental changes in OSA severity, from normal to severe, primarily affect the levels of resistin and other adipokines. Methods: Serum levels of resistin, interleukin-6 (IL-6) and leptin were examined in 31 men with OSA and 10 men without OSA, matched for age, body mass index (BMI) and several metabolic profiles. In 11 of the 31 men with OSA, these mediators were reexamined after 3 months of nasal continuous airway pressure (nCPAP) therapy. Results: Levels of resistin and IL- 6 were simultaneously elevated in men with OSA compared with those in men without OSA $(p<0.05)$, while levels of leptin did not differ. The resistin and IL-6 levels tended to increase with increasing disease severity $(p<0.05)$, which was based on the apnea-hypopnea index (AHI). The average oxyhemoglobin saturation during sleep $(p<0.01)$ and IL-6 $(p<0.05)$ emerged as significant determinants of resistin, even after adjustments for age, BMI, leptin levels and metabolic risk factors. After nCPAP therapy, the elevated levels of resistin and IL- 6 decreased, reaching almost base-
\end{abstract}

line levels of controls. Before treatment, AHI correlated positively with the reduction rate in resistin $(p<0.05)$. Conclusion: In OSA patients, resistin production can be enhanced by hypoxic stress during sleep, possibly mediating systemic inflammatory processes. nCPAP therapy may play a beneficial role in the control of resistin production.

Copyright $\odot 2008$ S. Karger AG, Basel

\section{Introduction}

Obstructive sleep apnea (OSA) is closely related to systemic inflammation [1]. A wide variety of pro-inflammatory mediators are elevated in the circulation of patients with OSA [2-7]. Additionally, OSA patients have peripheral leukocytes which can generate larger amounts of cytokines $[4,8]$, adhesion molecules [9] and free radicals [10]. The inflammatory milieu may be responsible for the development of vascular involvement in OSA [1]. Indeed, the degree of carotid atherosclerosis correlates positively with the respiratory disturbance index [11] and cytokine levels [12].

Systemic inflammation is closely related to insulin resistance and the metabolic syndrome, a cluster of cardiovascular risks including glucose intolerance [13-15]. Such metabolic disruptions coexist frequently in patients with OSA; in turn, the presence of OSA has emerged as an independent risk factor for insulin resistance [16-18] and the metabolic syndrome $[19,20]$. The association between

\section{KARGER}

Fax +4161306 1234 E-Mail karger@karger.ch www.karger.com
(C) 2008 S. Karger AG, Basel

0025-7931/08/0764-0377\$24.50/0

Accessible online at:

www.karger.com/res
Yasushi Yamamoto, MD

Department of Respiratory Medicine

National Hospital Organization, Dohoku Hospital

7-tyome, Hanasaki, Asahikawa, Hokkaido 070-8644 (Japan)

Tel. +81 16651 3161, Fax +81 16651 3119, E-Mail yasushiy@asahikawa.hosp.go.jp 
metabolic consequences in OSA and inflammation has not been fully elucidated. Resistin is an adipocyte-derived cytokine (adipokine) that may contribute to the development of obesity [21-24], insulin resistance $[25,26]$ and the metabolic syndrome [15]. More recent studies have shown the causative association between resistin and systemic inflammation $[27,28]$, especially in the vascular endothelium [29]. From the viewpoint of inflammation, it is notable that plasma resistin concentrations increase with increasing inflammatory mediator levels, predicting the severity of coronary atherosclerosis [30].

An investigation of resistin therefore provides a better understanding of complex links between OSA and metabolic disorders, inflammation and cardiovascular involvements. This issue has been addressed only by Harsch et al. [31], who examined serum resistin levels merely in patients with severe OSA, concluding that the pathophysiology of OSA is not related to resistin levels [31]. This disparity, however, derives from the selected population that lacks both appropriate controls and patients with milder forms of OSA. To detect a meaningful association, we conducted a cross-sectional survey of resistin, including subjects with a wide range of disease severity in the study.

The primary aim of the present study was to investigate whether the incremental changes in OSA severity, from normal to severe, primarily affect resistin levels. The secondary aim was to assess for associations between resistin and interleukin-6 (IL-6) and leptin, both of which belong to the adipokine family linking obesity with insulin resistance and inflammation [32-34]. We further evaluated the therapeutic effect of nasal continuous airway pressure (nCPAP) therapy on these mediators.

\section{Patients and Methods}

\section{Study Participants}

The Ethics Committee of the Dohoku Hospital approved this protocol, and all participants gave informed consent. Between January 2003 and March 2006, we consecutively recruited 31 men with newly defined OSA. None had undergone any treatment for OSA. The definition of OSA was based on a combination of clinical symptoms (i.e. daytime excessive sleepiness) and at least one round of a standard polysomnography. OSA was diagnosed when the apnea-hypopnea index (AHI) was $\geq 5$ events per hour. A total of 10 men, who snored but had an $\mathrm{AHI}$ of $<5$ events per hour, were randomly recruited as controls. They were matched for age, smoking status, body mass index (BMI), fasting plasma glucose, lipid profiles and the homeostasis model assessment (HOMA) index. Exclusion criteria were as follows: (1) age $>80$ years; (2) diabetes mellitus defined by fasting plasma glucose $\geq 126 \mathrm{mg} / \mathrm{dl}$; (3) ongoing medication for diabetes, dyslipidemia and hypertension; (4) current prescription of anti-inflammatory drugs and steroids; (5) the presence of any of the following medical conditions: clinically demonstrable chronic renal diseases, primary heart diseases and endocrine disorders; and finally (6) a history of a cardiovascular event or stroke.

\section{Design of the Cross-Sectional Study}

The cross-sectional association between untreated OSA and serum resistin levels was initially investigated. Following admission, smoking habits (never, current or former), medical history and regular medication use were recorded. Anthropometric data (height and weight) were recorded and BMI was then calculated as body weight $(\mathrm{kg})$ divided by height squared $\left(\mathrm{m}^{2}\right)$. Daytime blood pressure was measured at least twice between 8 and 11 a.m. after $10 \mathrm{~min}$ of rest in the supine position. In all subjects, chest roentgenogram, electrocardiogram and pulmonary function test were performed. Routine blood examinations included peripheral blood cell counts, liver enzymes, creatinine, fasting plasma glucose, fasting serum insulin, fasting serum triglycerides and high-density-lipoprotein cholesterol. Insulin resistance was evaluated using the HOMA index: plasma glucose $(\mathrm{mg} / \mathrm{dl}) \times$ insulin $(\mu \mathrm{U} / \mathrm{ml}) / 405[35]$.

Except for obesity, the components of the metabolic syndrome were defined according to standard criteria [14]. Definition of obesity was based on the recommendation for the Asian population [36]. The metabolic score was given as the summed number of the following components positively identified: (1) BMI $\geq 25$, (2) blood pressure $\geq 130 / 85 \mathrm{~mm} \mathrm{Hg}$, (3) elevation in serum triglycerides $\geq 150 \mathrm{mg} / \mathrm{dl}$, (4) reduction in serum high-density-lipoprotein cholesterol $<40 \mathrm{mg} / \mathrm{dl}$ and (5) fasting plasma glucose $\geq 110 \mathrm{mg} / \mathrm{dl}$. The metabolic syndrome was diagnosed when the metabolic score was $\geq 3$.

After polysomnography, fasting blood samples were taken between 7 and 8 a.m. to examine serum levels of resistin, IL- 6 and leptin at baseline. These mediator levels were compared between OSA patients and control subjects. Based on the AHI, OSA patients were subdivided into either the mild-to-moderate OSA group (AHI $=5-30$ events $/$ h) or the severe OSA group (AHI $\geq 30$ events/h). Analysis of covariance was then applied to investigate whether the incremental change in OSA severity can affect each mediator independently of age, BMI, smoking status and the metabolic score. Uni- and multivariate regression analyses were conducted within the entire population to identify significant predictors for each mediator. Stepwise multivariate regression models comprised explanatory variables including age, polysomnographic parameters, BMI, smoking status, the metabolic score and the HOMA index.

Design of the Follow-Up Study

Of the 31 patients with OSA, 11 underwent nCPAP therapy employing a device with an autotitrating system (Goodknight 420E; Tyco Healthcare, Tokyo, Japan). On the 2nd day from the induction, sleep parameters under nCPAP were obtained employing a portable monitor (Stardust; Respironics, Murrysville, Pa., USA). The median AHI was remarkably decreased after nCPAP therapy (from 39.9 to 5.5 events/h, p < 0.01). After 3 months of nCPAP therapy, anthropometric measurements and fasting blood collection were performed between 9 and 11 a.m. to examine BMI and serum levels of resistin and IL-6. Throughout the study, CPAP adherence was confirmed using the built-in data stores in the CPAP device. 


\section{Polysomnography}

Polysomnographic parameters were continuously recorded via a computerized data acquisition system (Alice-3; Healthdyne, Atlanta, Ga., USA). The following parameters were documented: sleep stage (electroencephalogram and electro-occulogram), electrocardiogram, nasal airflow, thoracic and abdominal movements and oxyhemoglobin saturation $\left(\mathrm{SpO}_{2}\right)$. Apnea was defined as complete cessation of nasal airflow for at least $10 \mathrm{~s}$. Hypopnea was defined as a $\geq 50 \%$ reduction in nasal airflow lasting at least $10 \mathrm{~s}$, with oxygen desaturation $\geq 3 \%$. The AHI was calculated as the average number of apnea plus hypopnea events per hour of sleep. The degree of nocturnal hypoxia was assessed using the percentage of time that $\mathrm{SpO}_{2}$ decreased below $90 \%$ during total sleep time (time $\mathrm{SpO}_{2}<90 \%$ ) and average $\mathrm{SpO}_{2}$ during sleep.

\section{Laboratory Assays}

Blood samples were centrifuged immediately after collection and separated serum was stored at $-80^{\circ} \mathrm{C}$ until assayed. Resistin, leptin, IL- 6 and insulin were measured by commercial enzymelinked immunosorbent assay kits (resistin and leptin, R \& D Systems, Minneapolis, Minn., USA; IL- 6 and insulin, BioSource International, Camarillo, Calif., USA). The intra- and interassay coefficients of variation in these assay kits ranged from 4 to $9 \%$. Plasma glucose levels were measured by the electrode method.

\section{Statistical Analysis}

Continuous variables are expressed as means $\pm \mathrm{SE}$, if normal distribution was accepted by the Kolmogorov-Smirnov test. Skewed variables are given as medians (interquartile ranges) and were logarithmically transformed prior to analysis. Comparison between OSA patients and controls was made using the unpaired $t$ test for continuous variables or the $\chi^{2}$ test for categorical data. Independent associations between disease severity of OSA and circulating mediators were evaluated by analysis of covariance, which consisted of age, BMI, smoking status and the metabolic score as covariates. Multiple comparisons were made using the test with Bonferroni correction. Univariate correlation was assessed using Pearson's correlation coefficients. The relative strength of the correlations was assessed using stepwise multivariate linear regression analysis. Differences in variables before and during nCPAP therapy were assessed using the paired t test. Statistical analysis was performed using SPSS (version 14.0; SPSS, Chicago, Ill., USA). $\mathrm{p}<0.05$ was considered statistically significant.

\section{Results}

\section{Baseline Characteristics of the Study Subjects}

The mean age and BMI, and the percentage of chronic smokers did not differ between control subjects and patients with OSA. Newly defined components of the metabolic syndrome are listed in table 1 . The metabolic score was modestly higher in patients with OSA ( $\mathrm{p}=$ 0.18 ), yielding a weak trend towards a higher incidence of the metabolic syndrome $(p=0.31)$. Hypertension was the only component diagnosed predominantly in patients
Table 1. Baseline characteristics

\begin{tabular}{lcc}
\hline & $\begin{array}{l}\text { Controls } \\
(\mathrm{AHI}<5 ; \mathrm{n}=10)\end{array}$ & $\begin{array}{l}\text { Patients with OSA } \\
(\mathrm{AHI} \geq 5 ; \mathrm{n}=31)\end{array}$ \\
\hline Age, years & $46 \pm 6$ & $49 \pm 2$ \\
BMI & $27 \pm 2$ & $28 \pm 1$ \\
Current plus former smokers & $5(50)$ & $19(61)$ \\
Metabolic score (range: 0-5) & $1.6 \pm 0.4$ & $2.2 \pm 0.2$ \\
Metabolic syndrome & $3(30)$ & $15(48)$ \\
$\quad$ Obesity & $8(80)$ & $20(65)$ \\
$\quad$ Hypertension & $2(20)$ & $22(71)^{*}$ \\
$\quad$ High triglycerides & $4(40)$ & $17(55)$ \\
$\quad$ Low HDL-C & $2(20)$ & $7(22)$ \\
$\quad$ Hyperglycemia & $2(20)$ & $2(7)$ \\
Fasting glucose, mg/dl & $93 \pm 6$ & $95 \pm 2$ \\
Insulin, $\mu$ U/ml & $18.3(6.8-43.5)$ & $10.9(7.7-22.0)$ \\
HOMA & $3.7(1.5-13.2)$ & $2.6(1.7-5.5)$ \\
\hline
\end{tabular}

Data are means $\pm \mathrm{SE}$, numbers (percentages) or medians (interquartile ranges).

${ }^{*} \mathrm{p}<0.05$. HDL-C $=$ High-density-lipoprotein cholesterol.

Table 2. Results of diagnostic polysomnography and adipokines at baseline

\begin{tabular}{lcc}
\hline & $\begin{array}{l}\text { Controls } \\
(\mathrm{AHI}<5 ; \mathrm{n}=10)\end{array}$ & $\begin{array}{l}\text { Patients with OSA } \\
(\mathrm{AHI} \geq 5 ; \mathrm{n}=31)\end{array}$ \\
\hline $\begin{array}{l}\text { Polysomnographic data } \\
\text { Total sleep time, min }\end{array}$ & $462 \pm 45$ & $416 \pm 13$ \\
AHI, events/h & $3.4 \pm 0.4$ & $33.1 \pm 4.0^{* *}$ \\
Time $\mathrm{SpO}_{2}<90 \%, \%$ & $0.1(0-0.9)$ & $7.7(2.3-32.8)^{* *}$ \\
$\quad$ Average $\mathrm{SpO}_{2}, \%$ & $95.3 \pm 0.6$ & $92.5 \pm 0.6^{* *}$ \\
Adipokines at baseline & & \\
$\quad$ Resistin, $\mathrm{ng} / \mathrm{ml}$ & $15.8(13.7-18.7)$ & $22.0(15.7-32.0)^{*}$ \\
IL-6, pg/ml & $1.9(1.3-3.2)$ & $4.0(3.4-7.6)^{* *}$ \\
Leptin, $\mathrm{ng} / \mathrm{ml}$ & $5.1(3.1-7.2)$ & $6.1(4.5-10.2)$ \\
\hline
\end{tabular}

Data are means \pm SE or medians (interquartile ranges).

${ }^{*} \mathrm{p}<0.05$ and ${ }^{* *} \mathrm{p}<0.01$ vs. controls. with OSA $(\mathrm{p}<0.01)$, while the other components were equally prevalent. No differences existed in fasting glucose levels, serum insulin concentrations and the HOMA index.

\section{Polysomnographic Evaluation and Baseline \\ Assessment of Adipokines}

Compared with control subjects, patients with OSA had greater AHI, longer time $\mathrm{SpO}_{2}<90 \%$ and lower average $\mathrm{SpO}_{2}$ during sleep time (table 2). AHI showed strik- 

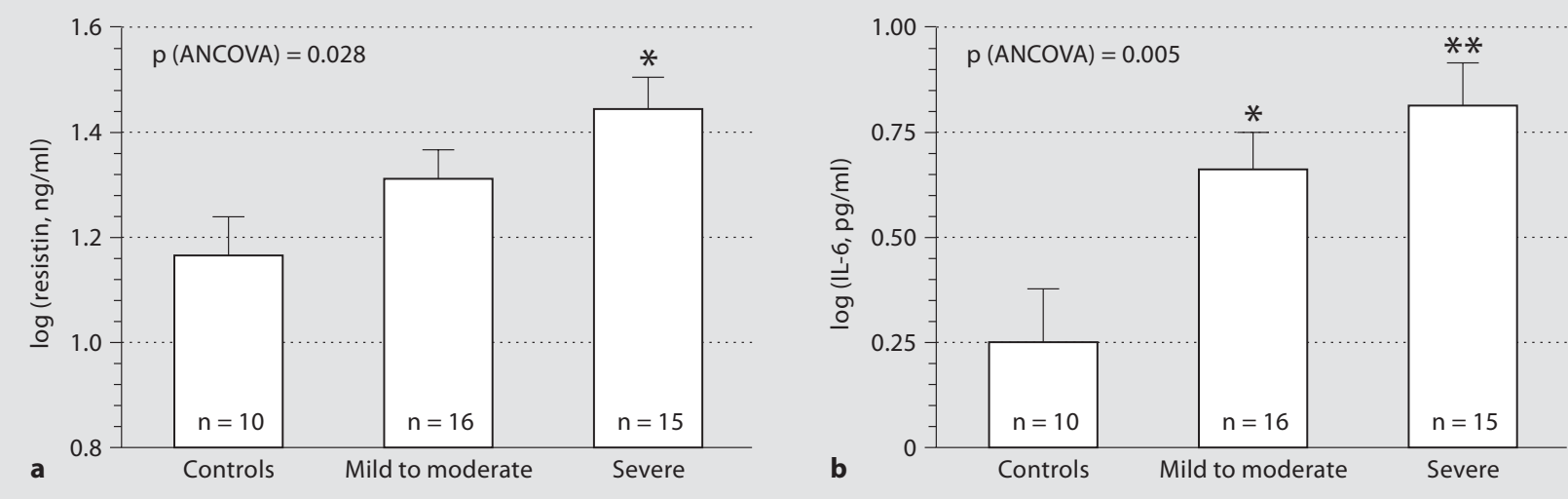

Fig. 1. log-transformed values of serum resistin (a) and IL- 6 (b) in controls $(\mathrm{AHI}<5)$, and patients with mildto-moderate (AHI 5-30) and severe OSA (AHI $\geq 30$ ). Values were adjusted for age, BMI, smoking status and the metabolic score. ${ }^{*} \mathrm{p}<0.05$ and ${ }^{* *} \mathrm{p}<0.01$ vs. controls.

ing univariate correlations with average $\mathrm{SpO}_{2}$ and time $\mathrm{SpO}_{2}<90 \%(\mathrm{r}=-0.737$ and $0.772, \mathrm{p}<0.0001)$. Of the 31 patients, 16 had mild-to-moderate OSA and 15 had severe OSA, with an average AHI of 16.1 and 51.1 events/h. There were no differences in the baseline characteristics between the two OSA subgroups (data not shown).

Serum levels of resistin and IL-6 were elevated in patients with OSA compared with controls $(\mathrm{p}<0.05$ and $\mathrm{p}<0.01$, respectively; table 2 ). In contrast, serum levels of leptin were similar between OSA patients and controls (table 2). When the study population was stratified into two groups based on the presence or absence of hypertension, there were no differences in resistin and IL-6 levels between the groups (data not shown).

To assess the effect of disease severity on resistin and IL-6, we developed analysis of covariance models consisting of age, BMI, smoking status and the metabolic score as covariates. Consequently, adjusted values of resistin ( $p=0.028)$ and IL-6 ( $p=0.005)$ tended to increase with increasing disease severity. Multiple comparisons revealed that resistin and IL-6 levels were higher in the subgroup with severe OSA than in the controls, independently of confounders ( $\mathrm{p}<0.05$ and $\mathrm{p}<0.01$, respectively; fig. 1).

\section{Association of Resistin with OSA and Systemic Inflammation}

Resistin had striking univariate correlations with AHI, time $\mathrm{SpO}_{2}<90 \%$, average $\mathrm{SpO}_{2}$ and IL- 6 ( $\mathrm{p}<0.01$ ), but not with markers of adiposity (BMI and leptin), the
Table 3. Univariate and multivariate regression analysis for resis$\operatorname{tin}^{1}(\mathrm{n}=41)$

\begin{tabular}{|c|c|c|c|c|}
\hline \multirow{2}{*}{$\begin{array}{l}\text { Independent } \\
\text { variables }\end{array}$} & \multicolumn{2}{|c|}{ Univariate } & \multicolumn{2}{|c|}{ Multivariate } \\
\hline & $\mathrm{r}$ & $\mathrm{p}$ & $\beta$ & $\mathrm{p}$ \\
\hline Age & 0.069 & NS & 0.015 & NS \\
\hline BMI & 0.106 & NS & -0.137 & NS \\
\hline Chronic smoking & 0.123 & NS & 0.115 & NS \\
\hline Metabolic score & -0.022 & NS & -0.056 & NS \\
\hline AHI & 0.451 & 0.002 & 0.070 & NS \\
\hline Time $\mathrm{SpO}_{2}<90 \%^{1}$ & 0.435 & 0.002 & -0.118 & NS \\
\hline Average $\mathrm{SpO}_{2}$ & -0.490 & 0.001 & -0.424 & 0.003 \\
\hline $\mathrm{HOMA}^{1}$ & -0.197 & NS & -0.206 & NS \\
\hline Leptin $^{1}$ & 0.060 & NS & -0.058 & NS \\
\hline IL-6 ${ }^{1}$ & 0.412 & 0.004 & 0.327 & 0.020 \\
\hline
\end{tabular}

${ }^{1}$ Variables are logarithmically transformed.

r values: Pearson's correlation coefficients; $\beta$ values: standardized parameter estimates.

metabolic score and the HOMA index (table 3). Likewise, IL- 6 correlated positively with $\mathrm{AHI}$, time $\mathrm{SpO}_{2}<90 \%$ and resistin $(\mathrm{r}=0.332,0.294$ and 0.412 , respectively, $\mathrm{p}<0.05)$. Leptin strongly correlated with BMI and the HOMA in$\operatorname{dex}(\mathrm{r}=0.444$ and 0.283 , respectively, $\mathrm{p}<0.05)$ but had a marginal link with AHI $(r=0.220, p=0.08)$.

As shown in table 3 and figure 2, resistin had independent linear relationships with average $\mathrm{SpO}_{2}(\mathrm{p}=0.003)$ and IL- $6(\mathrm{p}=0.02)$ in the multiple regression model con- 

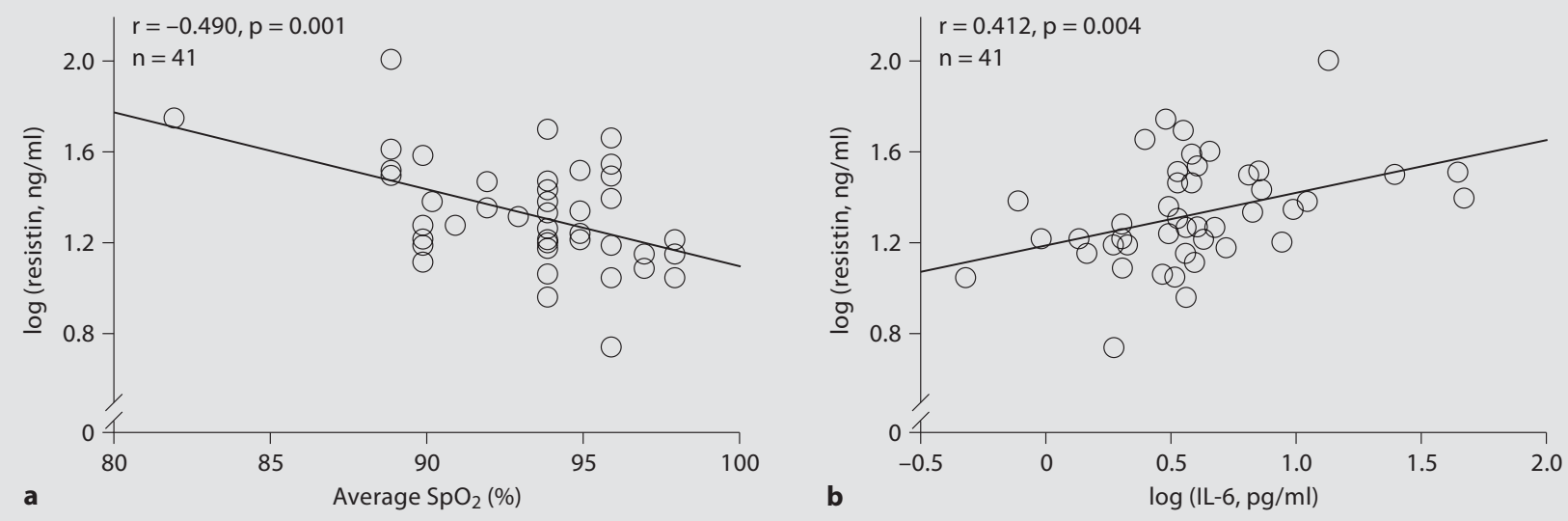

Fig. 2. Correlation between resistin and average $\mathrm{SpO}_{2}$ (a) and IL-6 (b) in the entire study population $(\mathrm{n}=41)$. $r$ values: Pearson's correlation coefficients.
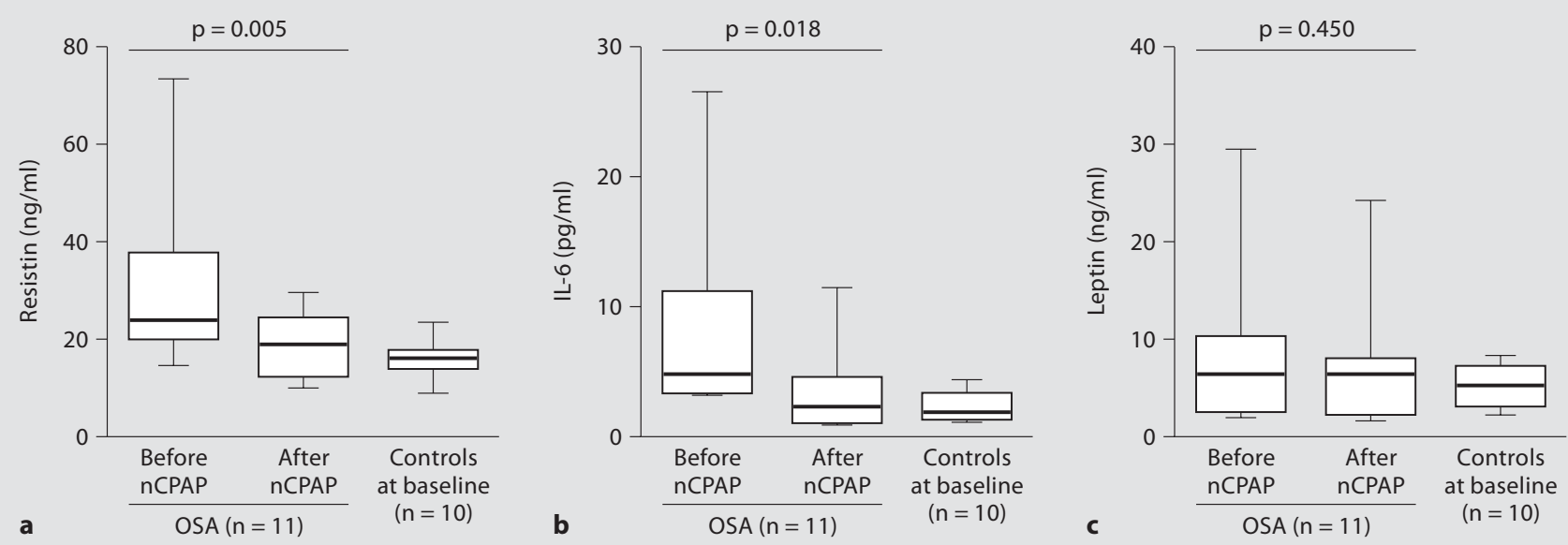

Fig. 3. Serum resistin (a), IL-6 (b) and leptin (c) levels before and after nCPAP therapy in patients with OSA $(\mathrm{n}=11)$ and those at baseline in controls $(\mathrm{n}=10)$. Box-whisker plots represent interquartile and data ranges. Horizontal lines within the box denote medians.

trolling for age, BMI, smoking status, the metabolic score, leptin and the HOMA index $\left(\mathrm{R}^{2}=0.343, \mathrm{p}<0.0001\right)$. This model could explain $34.3 \%$ of the variation in resistin. When average $\mathrm{SpO}_{2}$ and time $\mathrm{SpO}_{2}<90 \%$ were excluded from the regression model, AHI emerged as a significant predictor $\left(\mathrm{R}^{2}=0.203, \mathrm{p}=0.003\right)$.

In turn, the multiple regression model for IL-6 identified resistin as the only predictor $\left(\mathrm{R}^{2}=0.170, \mathrm{p}=0.007\right)$. When resistin was eliminated from the independent variables, AHI emerged as the only predictor of IL- $6\left(\mathrm{R}^{2}=\right.$ $0.110, p=0.034)$. These results indicated that AHI was significantly linked with resistin and IL-6, but its relative contribution appeared weaker than those of average $\mathrm{SpO}_{2}$ and resistin, respectively.

\section{Changes in Resistin and IL-6 Levels before and after $n C P A P$ Therapy}

After 3 months of nCPAP therapy, the CPAP compliance in 11 patients averaged at $5.1 \pm 0.4 \mathrm{~h} / \mathrm{night}$ (mean $\pm \mathrm{SE}$ ). BMI remained unchanged before and after nCPAP therapy (mean \pm SE: $29 \pm 2$ vs. $29 \pm 2$, p >0.05). In all cases, serum resistin levels were reduced after 


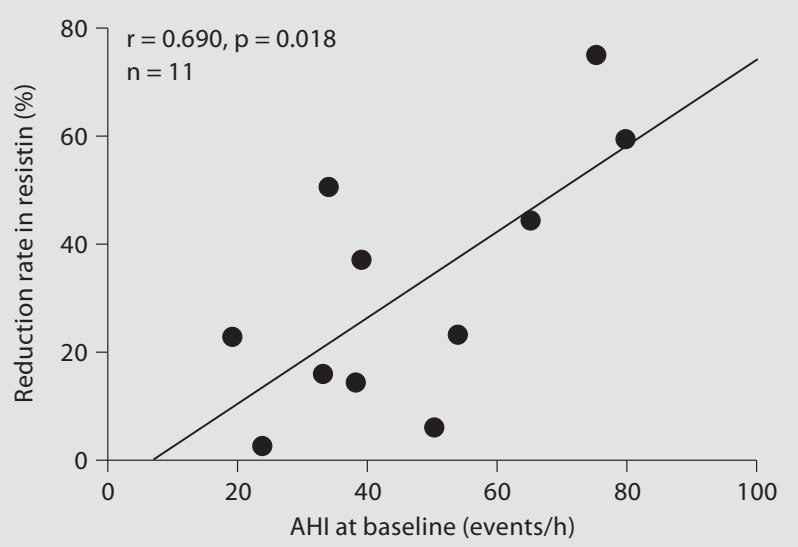

Fig. 4. Correlation between the baseline AHI and the reduction rate of resistin $(n=11)$. $r$ value: Pearson's correlation coefficient.

$\mathrm{nCPAP}(\mathrm{p}=0.005$; fig. 3). Levels of IL- 6 were also reduced compared with the values before treatment $(p=0.018)$, while leptin levels were unaltered (fig. 3).

After treatment, resistin and IL-6 levels approached baseline values in control subjects, whereas after treatment BMI was modestly greater than the baseline BMI in controls (means \pm SE: $29 \pm 2$ vs. $27 \pm 2$ ). Before treatment, AHI correlated positively to the reduction rates in resistin ( $\mathrm{r}=0.690, \mathrm{p}=0.018$; fig. 4 ), indicating that the baseline AHI could predict the reduction in resistin when OSA was successfully treated with nCPAP.

\section{Discussion}

We have demonstrated that untreated OSA patients had higher levels of serum resistin and IL- 6 than controls. These mediators were increased depending on the disease severity of OSA. The average $\mathrm{SpO}_{2}$ saturation during sleep and IL- 6 emerged as primary determinants of resistin. The cross-sectional association between OSA and resistin was independent of BMI, leptin levels and several metabolic risk factors. After nCPAP therapy, serum levels of resistin and IL- 6 were reduced, reaching almost baseline levels in controls. Before treatment, AHI was capable of predicting the reduction rate of resistin. These results indicate that OSA is independently associated with resistin, possibly mediating systemic inflammatory processes.
OSA has increasingly been associated with systemic inflammation [1]. We found that, for the first time, serum levels of resistin and IL-6 were simultaneously raised with increasing disease severity of OSA. The effect of AHI turned insignificant in multivariate linear regression analysis, probably due to the presence of independent variables showing co-linearity to AHI. Following exclusion of such variables, the modified models identified AHI as a primary predictor of both mediators. Removal of OSA by nCPAP resulted in the reduction of both resistin and IL-6 levels, without a change in the other adipokine, leptin. These results strongly suggest that the pathophysiology of OSA can activate resistin and IL-6 production simultaneously. It is noteworthy that a striking linkage existed between resistin and IL-6. This association was independent of BMI, even though both mediators originate partly from adipose tissue $[24,32]$. These results are in line with the earlier observation that peripheral monocytes, but not adipose tissue, are a major source of circulating IL-6 in patients with OSA [4]. We propose that the presence of OSA can activate peripheral leukocytes, promoting resistin and IL- 6 production through the common pathways. This notion can be explained based on the following evidence: first, circulating monocytes/macrophages emerge as major sources of resistin in humans [37]; second, resistin expression is regulated by the nuclear factor- $\kappa \mathrm{B}$ signaling pathway $[27,28]$, and, finally, circulating levels of resistin are positively correlated with those of soluble tumor necrosis factor- $\alpha$ receptor [38], IL-6 [30, 31] and C-reactive protein [39, 40]. Given the pro-inflammatory properties of resistin, OSA is likely to mediate resistin expression as a part of systemic inflammation. In addition, such putative mechanisms underlying the resistin production may distinctly differ from those of leptin.

The pathophysiological changes in OSA can activate peripheral neutrophils and monocytes, leading to enhanced generation of cytokines $[4,8]$, resulting in the elevated levels of pro-inflammatory mediators [2-7]. Nocturnal hypoxia has emerged as a primary candidate to enhance inflammatory cascades in OSA $[1,6,12,41]$. These facts support our finding that the average $\mathrm{SpO}_{2}$ during sleep was identified as a strong predictor of circulating resistin, leading to the question of whether hypoxia induces resistin production either directly or indirectly. We speculate that intermittent hypoxia may directly enhance resistin production during sleep, because cyclical stimulation of hypoxia selectively activates the nuclear factor- $\kappa \mathrm{B}$ signaling pathway in both in vitro experiments [41] and clinical studies [6]. This process may up- 
regulate resistin expression in circulating monocytes, leading to an increase in resistin release into the peripheral circulation.

The novel finding of this study was that OSA was closely associated with increased serum resistin levels, independently of BMI. In addition, obesity is unlikely to explain the increased resistin levels in OSA. Consequently, baseline levels of leptin did not differ between OSA patients and BMI-matched controls. This result suggests that visceral adiposity was similar between both groups, since circulating leptin levels can precisely reflect visceral fat volume [33, 42]. Our findings are consistent with clinical observations showing no apparent correlations between resistin and BMI, fat mass and waist circumference $[26,43]$. In contrast, several inflammatory markers are shown to correlate with resistin levels even after adjustment for BMI [38-40]. These facts support the notion that OSA-linked inflammation, but not obesity, plays a crucial role in the control of resistin production.

The missing link between resistin and obesity is also evidenced by in vitro studies. In freshly isolated adipocytes, resistin mRNA levels are quite low and show no correlation with BMI [37]. Although resistin gene expression is abundant in pre-adipocytes, it is down-regulated during adipogenic differentiation to mature adipocytes [44]. These facts strongly suggest that the ability to generate resistin is decreased in mature adipose tissue. It is therefore not surprising that body mass and leptin cannot predict resistin levels in the cross-sectional observation.

OSA is associated with altered levels of several adipokines including leptin $[18,45,46]$ and adiponectin [47, 48]. Circulating leptin levels have been found to increase with increasing sympathetic activity [45]. Given that resistin production is susceptible to autonomic regulation, it is conceivable that the sympathetic overflow in OSA augments both leptin and resistin production. This notion, however, seems unlikely because $\beta$-adrenergic stimulation can reduce resistin expression in cultured adipocytes [49]. In the present study, no independent correlation was detected between the levels of leptin and resistin, suggesting that these adipokines are generated through different regulatory mechanisms.

Another explanation for the altered adipokine levels comes from the impaired insulin sensitivity in OSA [18, 47]. In line with the present study, leptin is known to modulate obesity-linked insulin sensitivity [33, 42]. Adiponectin, an enhancer of insulin action, may be linked with insulin resistance in patients with OSA [47]. Unlike such adipokines, resistin appeared to dissociate with in- sulin resistance in the present study. The causative role of resistin in insulin resistance is still under debate. Many, but not all studies have denied the role of resistin in impaired insulin sensitivity $[22,23,40,43]$. Contrarily, some have implicated resistin in the pathogenesis of insulin resistance $[25,26]$ and the metabolic syndrome [15]. These metabolic disorders therefore may confound the effect of OSA on resistin. To exclude this possibility, we carefully matched cases and controls for several metabolic profiles. Consequently, resistin was found to increase in OSA patients, irrespective of leptin levels, the HOMA index and the metabolic score. Effective nCPAP therapy could reduce resistin and IL-6 levels without changes in BMI and leptin levels, indicating that resistin is closely related to systemic inflammation, but not to the metabolic consequences, in OSA.

Signs of premature atherosclerosis and endothelial dysfunction are detectable in OSA [11, 12, 50]. Atherogenic inflammatory cytokines are increased in the circulation of OSA patients, correlating to the degree of intima-media thickness [12]. Given that resistin can promote inflammation, the increase in resistin induced by OSA is likely to participate in the atherogenic process. Therefore, resistin can directly induce endothelial activation, upregulating endothelial expressions of adhesion molecules and chemokines [29]. These actions of resistin possibly augment leukocyte adhesion, consequently activating inflammatory responses in vascular endothelium [29]. Indeed, in a large-scale epidemiological study, high plasma resistin levels are capable of predicting the severity of coronary atherosclerosis [30]. Unfortunately, we did not examine arterial structures employing relevant physiological measures. Further study is needed to clarify any meaningful association between resistin and vascular reactivity in OSA.

There are some limitations to the interpretation of our observations. First, the present study depends on crosssectional observation within relative small samples. All study participants were free of known medicated diseases; however, mild hypertension (blood pressure >130/85 $\mathrm{mm} \mathrm{Hg}$ ) was more prevalent in OSA patients. Although subjects with or without hypertension had similar levels of resistin, our sample size was too small to detect statistically significant differences. Further study is needed to investigate resistin in otherwise healthy individuals without OSA. Second, we examined resistin only in men, because the gender dimorphism is present in serum or plasma resistin levels $[21,23,40]$. There is limitation on translating the results readily to women with OSA. Third, the question of whether an altered AHI has a linear relation- 
ship with the reduction in resistin levels remains to be answered, since an overnight polysomnography was not conducted after nCPAP evaluation. However, in all treated cases, nCPAP was considered effective on the 2nd day of assessment, and its adherence was maintained throughout the study period. Finally, the effects of hypoxia on resistin synthesis should be tested ex vivo using cultured adipocyte or extracted adipose tissue.
In conclusion, the present study demonstrates that resistin production in OSA patients can be enhanced by hypoxic stress during sleep, mediating inflammatory processes. Furthermore, nCPAP therapy may play a beneficial role in the control of resistin production.

\section{References}

1 Hatipoglu U, Rubinstein I: Inflammation and obstructive sleep apnea syndrome pathogenesis: a working hypothesis. Respiration 2003;70:665-671.

-2 Vgontzas AN, Papanicolaou DA, Bixler EO, Hopper K, Lotsikas A, Lin HM, Kales A, Chrousos GP: Sleep apnea and daytime sleepiness and fatigue: relation to visceral obesity, insulin resistance, and hypercytokinemia. J Clin Endocrinol Metab 2000;85: 1151-1158.

-3 Shamsuzzaman AS, Winnicki M, Lanfranchi P, Wolk R, Kara T, Accurso V, Somers VK: Elevated C-reactive protein in patients with obstructive sleep apnea. Circulation 2002;105:2462-2464

4 Yokoe T, Minoguchi K, Matsuo H, Oda N, Minoguchi H, Yoshino G, Hirano T, Adachi $\mathrm{M}$ : Elevated levels of $\mathrm{C}$-reactive protein and interleukin-6 in patients with obstructive sleep apnea syndrome are decreased by nasal continuous positive airway pressure. Circulation 2003;107:1129-1134

5 Ohga E, Tomita T, Wada H, Yamamoto H, Nagase T, Ouchi Y: Effects of obstructive sleep apnea on circulating ICAM-1, IL-8, and MCP-1. J Appl Physiol 2003;94:179 184.

6 Ryan S, Taylor CT, McNicholas WT: Predictors of elevated nuclear factor- $\mathrm{\kappa} \mathrm{B}$-dependent genes in obstructive sleep apnea syndrome. Am J Respir Crit Care Med 2006;174:824830 .

7 Zouaoui Boudjeltia K, Van Meerhaeghe A, Doumit S, Guillaume M, Cauchie P, Brohee D, Vanhaeverbeek M, Kerkhofs M: Sleep apnoea-hypopnoea index is an independent predictor of high-sensitivity C-reactive protein elevation. Respiration 2006;73:243246.

$>8$ Minoguchi K, Tazaki T, Yokoe T, Minoguchi H, Watanabe Y, Yamamoto M, Adachi M: Elevated production of tumor necrosis factor$\alpha$ by monocytes in patients with obstructive sleep apnea syndrome. Chest 2004;126: 1473-1479.

$\checkmark 9$ Dyugovskaya L, Lavie P, Lavie L: Increased adhesion molecules expression and production of reactive oxygen species in leukocytes of sleep apnea patients. Am J Respir Crit Care Med 2002;165:934-939.
10 Schulz R, Mahmoudi S, Hattar K, Sibelius U, Olschewski H, Mayer K, Seeger W, Grimminger F: Enhanced release of superoxide from polymorphonuclear neutrophils in obstructive sleep apnea. Impact of continuous positive airway pressure therapy. Am J Respir Crit Care Med 2000;162:566-570.

11 Tanriverdi H, Evrengul H, Kara CO, Kuru O, Tanriverdi S, Ozkurt S, Kaftan A, Kilic M: Aortic stiffness, flow-mediated dilatation and carotid intima-media thickness in obstructive sleep apnea: non-invasive indicators of atherosclerosis. Respiration 2006;73: 741-750.

12 Minoguchi K, Yokoe T, Tazaki T, Minoguchi H, Tanaka A, Oda N, Okada S, Ohta S, Naito $\mathrm{H}$, Adachi $\mathrm{M}$ : Increased carotid intima-media thickness and serum inflammatory markers in obstructive sleep apnea. Am J Respir Crit Care Med 2005;172:625-630.

13 Festa A, D’Agostino R Jr, Howard G, Mykkanen L, Tracy RP, Haffner SM: Chronic subclinical inflammation as part of the insulin resistance syndrome: the insulin resistance atherosclerosis study (IRAS). Circulation 2000;102:42-47.

14 Executive Summary of the Third Report of the National Cholesterol Education Program (NCEP) Expert Panel on Detection, Evaluation, and Treatment of High Blood Cholesterol in Adults (Adult Treatment Panel III) JAMA 2001;285:2486-2497.

-15 Szapary PO, Bloedon LT, Samaha FF, Duffy D, Wolfe ML, Soffer D, Reilly MP, Chittams J, Rader DJ: Effects of pioglitazone on lipoproteins, inflammatory markers, and adipokines in nondiabetic patients with metabolic syndrome. Arterioscler Thromb Vasc Biol 2006;26:182-188.

-16 Ip MS, Lam B, Ng MM, Lam WK, Tsang KW, Lam KS: Obstructive sleep apnea is independently associated with insulin resistance. Am J Respir Crit Care Med 2002;165:670 676.

17 Punjabi NM, Shahar E, Redline S, Gottlieb DJ, Givelber R, Resnick HE: Sleep-disordered breathing, glucose intolerance, and insulin resistance: the Sleep Heart Health Study. Am J Epidemiol 2004;160:521-530.
18 McArdle N, Hillman D, Beilin L, Watts G: Metabolic risk factors for vascular disease in obstructive sleep apnea: a matched controlled study. Am J Respir Crit Care Med 2007;175:190-195.

19 Coughlin SR, Mawdsley L, Mugarza JA, Calverley PM, Wilding JP: Obstructive sleep apnoea is independently associated with an increased prevalence of metabolic syndrome. Eur Heart J 2004;25:735-741.

20 Lam JC, Lam B, Lam CL, Fong D, Wang JK, Tse HF, Lam KS, Ip MS: Obstructive sleep apnea and the metabolic syndrome in community-based Chinese adults in Hong Kong. Respir Med 2006;100:980-987.

-21 Yannakoulia M, Yiannakouris N, Bluher S, Matalas AL, Klimis-Zacas D, Mantzoros CS: Body fat mass and macronutrient intake in relation to circulating soluble leptin receptor, free leptin index, adiponectin, and resistin concentrations in healthy humans. J Clin Endocrinol Metab 2003;88:1730-1736.

22 Vozarova de Courten B, Degawa-Yamauchi M, Considine RV, Tataranni PA: High serum resistin is associated with an increase in adiposity but not a worsening of insulin resistance in Pima Indians. Diabetes 2004;53: 1279-1284.

23 Degawa-Yamauchi M, Bovenkerk JE, Juliar BE, Watson W, Kerr K, Jones R, Zhu Q, Considine RV: Serum resistin (FIZZ3) protein is increased in obese humans. J Clin Endocrinol Metab 2003;88:5452-5455

24 McTernan PG, McTernan CL, Chetty R, Jenner K, Fisher FM, Lauer MN, Crocker J, Barnett $\mathrm{AH}$, Kumar S: Increased resistin gene and protein expression in human abdominal adipose tissue. J Clin Endocrinol Metab 2002;87:2407.

25 McTernan PG, Fisher FM, Valsamakis G, Chetty R, Harte A, McTernan CL, Clark PM, Smith SA, Barnett AH, Kumar S: Resistin and type 2 diabetes: regulation of resistin expression by insulin and rosiglitazone and the effects of recombinant resistin on lipid and glucose metabolism in human differentiated adipocytes. J Clin Endocrinol Metab 2003; 88:6098-6106. 
-26 Silha JV, Krsek M, Skrha JV, Sucharda P, Nyomba BL, Murphy LJ: Plasma resistin, adiponectin and leptin levels in lean and obese subjects: correlations with insulin resistance. Eur J Endocrinol 2003;149:331-335.

27 Lehrke M, Reilly MP, Millington SC, Iqbal N, Rader DJ, Lazar MA: An inflammatory cascade leading to hyperresistinemia in humans. PLoS Med 2004;1:e45.

-28 Bokarewa M, Nagaev I, Dahlberg L, Smith U, Tarkowski A: Resistin, an adipokine with potent proinflammatory properties. J Immunol 2005;174:5789-5795.

-29 Verma S, Li SH, Wang CH, Fedak PW, Li RK, Weisel RD, Mickle DA: Resistin promotes endothelial cell activation: further evidence of adipokine-endothelial interaction. Circulation 2003;108:736-740

>30 Reilly MP, Lehrke M, Wolfe ML, Rohatgi A, Lazar MA, Rader DJ: Resistin is an inflammatory marker of atherosclerosis in humans. Circulation 2005;111:932-939.

31 Harsch IA, Koebnick C, Wallaschofski H, Schahin SP, Hahn EG, Ficker JH, Lohmann T, Konturek PC: Resistin levels in patients with obstructive sleep apnoea syndrome the link to subclinical inflammation? Med Sci Monit 2004;10:CR510-CR515.

>32 Kern PA, Ranganathan S, Li C, Wood L, Ranganathan G: Adipose tissue tumor necrosis factor and interleukin-6 expression in human obesity and insulin resistance. Am J Physiol Endocrinol Metab 2001;280:E745E751.

$\checkmark 33$ Zimmet P, Hodge A, Nicolson M, Staten M, de Courten M, Moore J, Morawiecki A, Lubina J, Collier G, Alberti G, Dowse G: Serum leptin concentration, obesity, and insulin resistance in Western Samoans: cross sectional study. BMJ 1996;313:965-969.

-34 Bullo M, Garcia-Lorda P, Megias I, Salas-Salvado J: Systemic inflammation, adipose tissue tumor necrosis factor, and leptin expression. Obes Res 2003;11:525-531.
35 Matthews DR, Hosker JP, Rudenski AS, Naylor BA, Treacher DF, Turner RC: Homeostasis model assessment: insulin resistance and $\beta$-cell function from fasting plasma glucose and insulin concentrations in man. Diabetologia 1985;28:412-419.

36 Steering Committee: The Asia-Pacific Perspective: Redefining Obesity and Its Treatment. Health Communications Australia, 2000, http://www.diabetes.com.au/pdf/obesity_report.pdf.

37 Savage DB, Sewter CP, Klenk ES, Segal DG Vidal-Puig A, Considine RV, O'Rahilly S: Resistin/Fizz3 expression in relation to obesity and peroxisome proliferator-activated receptor- $\gamma$ action in humans. Diabetes 2001 50:2199-2202.

38 Vendrell J, Broch M, Vilarrasa N, Molina A, Gomez JM, Gutierrez C, Simon I, Soler J, Richart C: Resistin, adiponectin, ghrelin, leptin, and proinflammatory cytokines: relationships in obesity. Obes Res 2004;12: 962-971.

39 Shetty GK, Economides PA, Horton ES Mantzoros CS, Veves A: Circulating adiponectin and resistin levels in relation to metabolic factors, inflammatory markers, and vascular reactivity in diabetic patients and subjects at risk for diabetes. Diabetes Care 2004;27:2450-2457.

40 Kunnari A, Ukkola O, Paivansalo M, Kesaniemi YA: High plasma resistin level is associated with enhanced highly sensitive Creactive protein and leukocytes. J Clin Endocrinol Metab 2006;91:2755-2760.

41 Ryan S, Taylor CT, McNicholas WT: Selective activation of inflammatory pathways by intermittent hypoxia in obstructive sleep apnea syndrome. Circulation 2005;112:2660 2667.

42 Cnop M, Landchild MJ, Vidal J, Havel PJ, Knowles NG, Carr DR, Wang F, Hull RL, Boyko EJ, Retzlaff BM, Walden CE, Knopp RH, Kahn SE: The concurrent accumulation of intra-abdominal and subcutaneous fat explains the association between insulin resistance and plasma leptin concentrations: distinct metabolic effects of two fat compartments. Diabetes 2002;51:1005-1015.
43 Lee JH, Chan JL, Yiannakouris N, Kontogianni M, Estrada E, Seip R, Orlova C, Mantzoros CS: Circulating resistin levels are not associated with obesity or insulin resistance in humans and are not regulated by fasting or leptin administration: cross-sectional and interventional studies in normal, insulin-resistant, and diabetic subjects. J Clin Endocrinol Metab 2003;88:4848-4856.

44 Janke J, Engeli S, Gorzelniak K, Luft FC, Sharma AM: Resistin gene expression in human adipocytes is not related to insulin resistance. Obes Res 2002;10:1-5.

45 Phillips BG, Kato M, Narkiewicz K, Choe I, Somers VK: Increases in leptin levels, sympathetic drive, and weight gain in obstructive sleep apnea. Am J Physiol Heart Circ Physiol 2000;279:H234-H237.

46 Ulukavak Ciftci T, Kokturk O, Bukan N, Bilgihan A: Leptin and ghrelin levels in patients with obstructive sleep apnea syndrome. Respiration 2005;72:395-401.

47 Harsch IA, Wallaschofski H, Koebnick C, Pour Schahin S, Hahn EG, Ficker JH, Lohmann T: Adiponectin in patients with obstructive sleep apnea syndrome: course and physiological relevance. Respiration 2004; 71:580-586.

48 Zhang XL, Yin KS, Wang H, Su S: Serum adiponectin levels in adult male patients with obstructive sleep apnea hypopnea syndrome. Respiration 2006;73:73-77.

49 Fasshauer M, Klein J, Neumann S, Eszlinger $\mathrm{M}$, Paschke R: Isoproterenol inhibits resistin gene expression through a $\mathrm{G}(\mathrm{S})$-proteincoupled pathway in 3T3-L1 adipocytes. FEBS Lett 2001;500:60-63.

50 Oflaz H, Cuhadaroglu C, Pamukcu B, Meric M, Ece T, Kasikcioglu E, Koylan N: Endothelial function in patients with obstructive sleep apnea syndrome but without hypertension. Respiration 2006;73:751-756. 